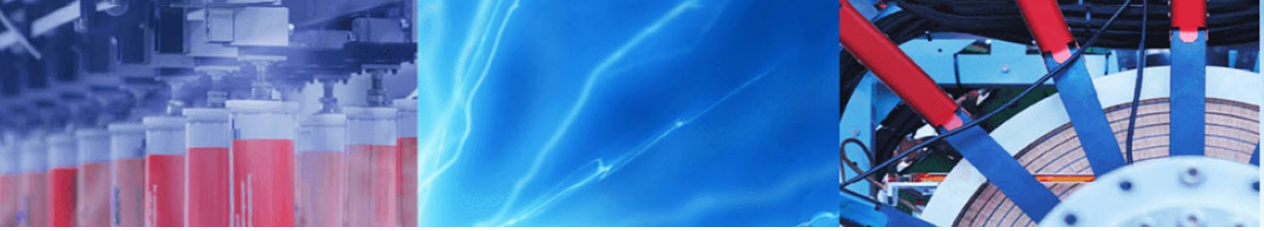

Research Article

\title{
Modelling and optimization of mean thickness of backward flow formed tubes using regression analysis, particle swarm optimization and neural network
}

\author{
Prabas Banerjee ${ }^{1}$ - Nirmal Baran Hui ${ }^{1} \cdot$ Mithilesh K. Dikshit ${ }^{2} \cdot$ Rupam Laha $^{1} \cdot$ Sandeep Das ${ }^{1}$
}

Received: 3 January 2020 / Accepted: 22 June 2020 / Published online: 8 July 2020

(c) Springer Nature Switzerland AG 2020

\begin{abstract}
In this study, the relationship between the input process parameters and the output parameters of the backward metal flow forming process is established using a full factorial design of experiments. Both the linear and interaction terms of the process variables have been analyzed using statistical methods. Composite desirability and particle swarm optimization (PSO) is used to find an optimal set of process parameters for the desired responses. The composite desirability approach was found to provide more accurate results compared to the PSO. Neural network (NN) was used for modelling the flow forming process for the efficient prediction of output parameters. The performance of the NN-based predictive tool is better compared to regression analysis.
\end{abstract}

Keywords Backward flow forming · Regression analysis - Composite desirability function · Particle swarm optimization . Neural network

$\begin{array}{ll}\text { Abbreviations } \\ \text { AS } & \text { Axial stagger of roller } \\ \text { IF } & \text { Infeed of roller } \\ \text { FS } & \text { Feed speed ratio of roller } \\ N & \text { Rotational velocity of mandrel }\end{array}$

\section{Introduction}

The cold backward metal flow forming process is popularly employed for the manufacturing of long cylindrical tubes. Multiple reductions are achieved with the help of more than one roller in one pass. The simple tooling arrangement, near net shape, and excellent surface finish are some of the major highlights of this process. From the early ' $70 \mathrm{~s}$, mechanics of the flow forming process has been an area of great interest for researchers. Experimental methodologies were designed to predict the forces and to understand the effect of various forming parameters. The pioneering works of Hayama and Kudo [1] and Nagaranjan et al. [2] could be considered as a benchmark for experimental analysis of the forming forces and the quality of flow formed tubes. Works of Thamasett [3], Gur, and Tirosh [4] is also regarded as a valuable contribution to the theoretical approaches employed to predict the forming forces. Singhal et al. [5] used an upper bound energy approach method to develop the relationship between forces and the forming parameters.

Some researchers [6-8] have experimentally investigated various flow forming parameters on the quality of flow-formed products such as hardness, out of roundness, diametral growth, and occurrence of a crack in flowformed tubes. Molladavoudi and Djavanroodi [9] studied the effect of reduction on various mechanical properties

$\triangle$ Prabas Banerjee, prabasbanerjee@gmail.com; Nirmal Baran Hui, nirmal.hui@me.nitdgp.ac.in; Mithilesh K. Dikshit, dixit.mithilesh@gmail.com; Rupam Laha, laharupam0709@gmail.com; Sandeep Das, sandeep12323das@gmail.com | 1Department of Mechanical Engineering, NIT Durgapur, Durgapur, W.B, India. ${ }^{2}$ Department of Mechanical Engineering, Institute of Infrastructure, Technology, Research and Management (IITRAM), Ahmedabad, Gujarat, India. 
such as elongation, surface roughness, and yield strength and thickness variation. Some of the researchers tried to solve this complex incremental forming process using statistical methods, where effort was given to draw inference between the input and the output parameters. These methods include regression analysis, response surface methodology, Taguchi method, and others. Notable works of Davidson et al. [10], Nahrekhalaji [11], Aghchai et al. [12] and Podder et al. [13] are essential to mention. Davidson et al. [10] used the Taguchi method to identify factors that affect the quality of flow formed material. The factors considered in their investigation were feed rate, depth of cut, and speed of mandrel. Nahrekhalaji [11] used a fractional factorial method to investigate input factors on the mean thickness of the spun products. The input factors considered are percentage reduction, axial feed of roller, a rotational speed of the mandrel, the initial thickness of the workpiece, and solution time for heat treatment. Podder et al. [13] studied the effect of various input parameters on output parameters of backward flow formed cylindrical tube considering full factorial design methodology. Srinivasulu et al. [14] used the Box-Benknen approach to study the diameter of flow formed tubes. The factors considered were the spindle speed, axial feed, and radius of rollers. Feed speed ratio of the rollers, infeed, or percentage reduction is some of the essential forming parameters which are considered in literature [13]. There are also some other critical forming parameters such as the dimension of the roller, forming forces and axial stagger of rollers. These forming parameters are not considered in the literature, which may significantly impact on the quality and productivity of the forming process [13].

Many researchers have modelled the metal flow forming process with the help of FEM, such as the work of Wong et al. [15]. Parsa et al. [16] studied formability by considering the effect of feed rate and attack angles with change in circumferential and axial contact length. Song et al. [17] investigated the dimensional aspect of the forward flow formed cylindrical tubes and reported a thickness variation along the axial length of the pipes. Xu et al. [18] studied the mandrel deflection during the process of analyzing the effect orientation of multiple rollers. There is very few literature available on the investigation of the effects of forming parameters on the formed wall thickness. Given the numerous advantages of this process, one of the significant drawbacks of this process is the variation of mean thickness along the axial length of the flow formed tube. This drawback enhances internal diameter growth. Thus, the factors which affect such a defect should be identified, and understanding of the process parameters affecting the mean thickness.

After the brief introduction, this research is divided in six sections. Section "Statement of the problem" introduces to the formulation of the problem. Section "Experimental details" discusses the experimental setup of the backward flow forming process. Section "Modelling of three rollers backward metal flow forming process" discusses the different statistical techniques employed for modeling of backward flow forming process. The penultimate section "Results and discussions" analysis the different results obtained from different statistical techniques used in this research study. The last section, "Conclusion," concludes the paper.

\section{Statement of the problem}

The present work deals with the modeling of the mean thickness of cylindrical tubes by backward metal flow forming process. The objective of the current investigation is to establish relationships between the process parameters (inputs) and responses (outputs) for the mean thickness of flow formed cylindrical tubes using regression analysis. Experiments are carried based on the fullfactorial design of experiments (DOE). Also, optimum flow forming conditions for the desired mean thickness is determined by composite desirability function and particle swarm optimization (PSO). A neural network model of the mean thickness is developed for efficient prediction of mean thickness for a given set of input conditions. Figure 1 shows a schematic representation of the input and the output parameters.

\section{Experimental details}

A brief introduction to the experimental setup is mentioned below.

\subsection{Experimental setup}

Experiments are conducted on a 3-roller, 4-axes CNC machine. Figure 2 shows the $\mathrm{CNC}$ machine used during experimentation.

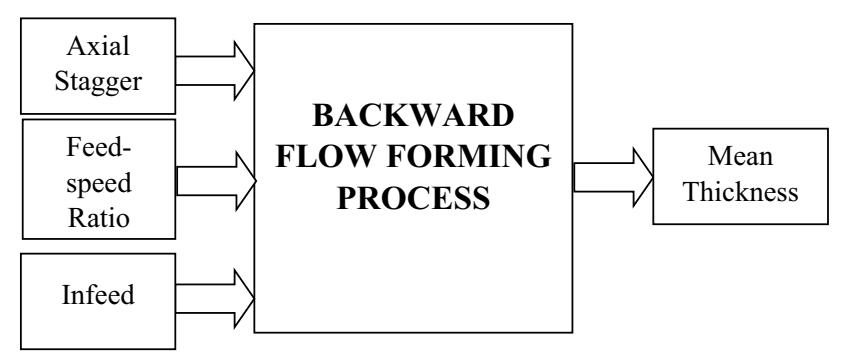

Fig. 1 Input and output parameters of a backward flow forming process 


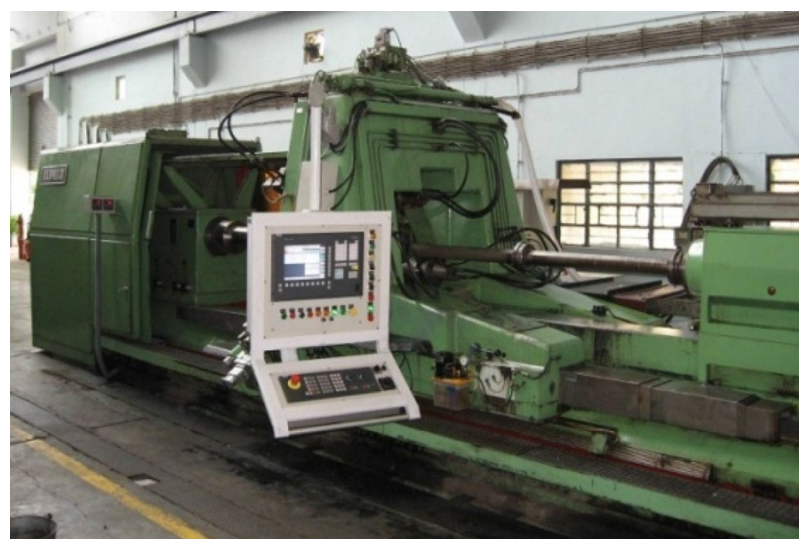

Fig. 2 Three-axis CNC flow forming machine (Make: Leifield, Germany) [13]

Preform material: AA6068 aluminum alloy is used as the raw material, which is a hollow cylindrical tube of $118 \mathrm{~mm}$ and $132 \mathrm{~mm}$ as internal and external diameters, respectively, and has an initial length of $180 \mathrm{~mm}$. Table 2 shows the chemical composition of the preform material used in the experiments.

Tooling required for flow forming: Some of the necessary toolings for forming are mandrel, stripper ring, toothed ring (usually known as driver ring), and forming rollers. The mandrel is made of AISI steel. The diameter of the mandrel is the same as the internal diameter of the preform. The stripper and toothed ring are assembled with a key fitted in a keyway. This assembly helps the preform to have the same rotational velocity as that of the mandrel. This arrangement restricts the forming of material in the direction of the traversing roller. The rollers are the main component as they help in the deformation of the material. The rollers are set to the desired thickness reduction, and they travel along the entire axial length of the preform. The rollers are arranged in rotational and in axial stagger, which aids in multiple reductions in one pass. In these experiments, three rollers are used, which are arranged at an angle of $120^{\circ}$ apart from each other [19].

Measurement of the mean thickness of flow formed tubes: Fig. 3 shows the measuring instrument for measuring the thickness of the flow formed tubes. A sound pulse is generated by a small probe, and the time is calculated for travel of sound through the thickness of the preform and travel back.

Process parameters: Three process parameters are considered for the design of experiments. The three process parameters are axial stagger (AS), feed speed ratio (FS), and infeed (IF). The axial stagger is one of the

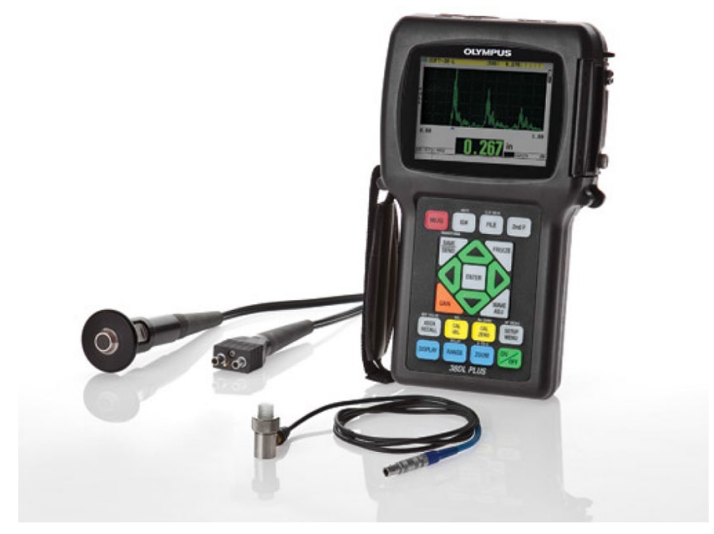

Fig. 3 Ultra sonic thickness gauge (Make: Olympus, Model: 38 DL Plus)

techniques employed for achieving multiple reductions in one pass. The rollers initially at the free end of the preform are arranged along the axial length of the preform. Axial stagger is the distance between the first roller and the last roller. Axial stagger arrangement is often made for achieving multi reduction during one pass. The infeed is the desired thickness reduction to be achieved during one forming operation. The desired thickness reduction is equally divided among the three rollers. For example, for a reduction of $3.5 \mathrm{~mm}$, the infeed for the first roller is $1.2 \mathrm{~mm}$, infeed for the second roller is $1.2 \mathrm{~mm}$, and the infeed of the last roller is $1.1 \mathrm{~mm}$. Such arrangement enhances the productivity of this forming process. The feed speed ratio is the ratio between the axial velocity of the roller and the rotational velocity of the mandrel. For different feed speed ratios, the feed of the roller is varied while the rotational velocity of the mandrel remains constant. For example, a feed speed ratio of $0.7 \mathrm{~mm} / \mathrm{rev}$ implies that the axial velocity of the roller is $70 \mathrm{~mm} / \mathrm{min}$ while the rotational velocity of the mandrel is 100 revolution per minute (RPM). In the pioneering work of Hayama and Kudo [1] among the different forming parameters, two forming parameters, such as thickness reduction and feed speed ratio, is considered. The effect of these parameters on the quality of flow formed cylindrical tubes were analyzed. Thus, in this study, the infeed and feed speed ratio are considered for analyzing their effect on the mean thickness of the flow formed tubes. Axial stagger of roller enhances the productivity of this forming process. Thus, the impact of this parameter is also considered as it dramatically impacts the productivity of the process. 


\section{Modeling of three roller backward metal flow forming process}

\subsection{Full-factorial DOE}

The chosen input parameters in this study are as follows: feed speed ratio, axial stagger, and infeed. Four levels are considered for each of the three input process parameters (refer to Table 1 ) so that $4^{3}=64$ combinations of input process parameters are to be considered for fullfactorial DOE [13]. The influence of each parameter was analyzed using the ANOVA technique, and regression analysis are done to get the relationship among them. A linear multiple regression analysis has been conducted on the experiment as per the full factorial design of experiments. Here, a single equation relating to one response to the process parameters for the whole domain is considered.

\subsection{Identification of optimal process parameters using particle swarm optimization}

Particle Swarm optimization (PSO) is an evolution-based search method that searches for the optimal solution in the predefined search space by updating the velocity and hence positions of the particles. Some of the researchers have also used it for modelling the flow forming process. Han et al. [20] used FEM to model the process, and the simulated results were trained with the PSO-NN technique to predict the spring back with varying input parameters. Kumar and Singh used the modified particle swarm optimization technique for the determination of optimal injection molding conditions for minimization of warpage and shrinkage. [21] PSO has been applied to predict the optimum input and output responses for a given response target value.

Table 1 Input Factors and their respective levels-Backward flow forming process

\begin{tabular}{lllll}
\hline Inputs & Level 1 & Level 2 & Level 3 & Level 4 \\
\hline Axial stagger (AS), mm & 9.5 & 11 & 12.5 & 14 \\
Feed speed ratio (FS), mm/rev & 0.5 & 0.6 & 0.7 & 0.8 \\
Infeed (IF), mm & 3.0 & 3.5 & 4.0 & 4.5 \\
\hline
\end{tabular}

\subsection{Modeling using a neural network (NN) technique}

A multi-layer feed-forward neural network is used for the prediction of mean thickness. Neural network studies were applied to other metal forming processes. For example, Kim and Kim [22] used NN to predict the amount of unfulfilled cavity for randomly chosen components. Hsiang and Ho [23] used NN to model the relationship between radial forging loads and die geometry. Similarly, Ashhab et al. [24] considered it for modelling the input and output parameters of an extrusion process. Luca [25] applied a radial basis function $\mathrm{NN}$ for modelling the technological input parameters of the electro-magnetic deformation process for the determination of the deformation of Fepo4 steel sheets. The author concluded that the model could be viable with the existing methods in the literature. Podder et al. [26] used Back propagation neural network and genetic algorithm neural network for the prediction of the final dimension of the flow formed tubes.

For the present purpose, the multi-layer NN architecture has been considered. Three inputs represent three neurons in the first layer, and in the output layer there exists only one neuron representing the mean thickness of the tubes. Multiple hidden layers have been considered, and numbers of neurons are varied to get an optimal architecture. For training purposes, half mean square error (HSME) of the output was found to be the objective function, and backpropagation based training was adopted [27].

\section{Results and discussions}

This section discusses the findings obtained from the Analysis of variance. The optimum parameters obtained from composite desirability approach and PSO are compared. Neural network is used for efficient prediction of mean thickness for a set of input parameters.

\subsection{Analysis of variance for mean thickness}

Fit summary for the mean thickness of the aluminum tube has been obtained using Analysis of Variance (ANOVA) performed with at $99 \%$ confidence, i.e., $a=0.01$ (refer to Table 2). Firstly, the adequacy of the model has been checked using the F-value and $p$ value of the model. From Table 3 , it can be seen that the F-value of the model is very high, and consequently, the $p$ value is less than 0.01 for most of the terms. Furthermore, from the standard probability plot (refer to
Table 2 Chemical composition (wt. \%) of the preform

\begin{tabular}{lllllllll}
\hline $\mathrm{C}$ & $\mathrm{Si}$ & $\mathrm{Mn}$ & $\mathrm{S}$ & $\mathrm{Ni}$ & $\mathrm{Cr}$ & $\mathrm{Co}$ & $\mathrm{Ti}$ & $\mathrm{Cu}$ \\
\hline 0.18 & 0.18 & 0.95 & 0.015 & 18.1 & 0.40 & 7.9 & 0.4 & 0.4 \\
\hline
\end{tabular}


Table 3 ANOVA and fit summary of mean thickness

\begin{tabular}{lrrrr}
\hline Source & DoF & \multicolumn{1}{c}{ Adj SS } & F-Value & $p$ value \\
\hline Model & 36 & 17.5978 & 31.37 & 0.000 \\
Linear & 9 & 17.0977 & 121.92 & 0.000 \\
AS & 3 & 0.0960 & 2.05 & 0.130 \\
IF & 3 & 16.9107 & 361.77 & 0.000 \\
FS & 3 & 0.0911 & 1.95 & 0.146 \\
2-Way Interactions & 27 & 0.5001 & 1.19 & 0.328 \\
AS*IF & 9 & 0.1723 & 1.23 & 0.319 \\
AS*FS & 9 & 0.1624 & 1.16 & 0.359 \\
IF*FS & 9 & 0.1654 & 1.18 & 0.347 \\
Error & 27 & 0.4207 & & \\
Total & 63 & 18.0185 & & \\
R $^{2}=97.67 \% \mathrm{R}^{2}$-(adj) $=94.55 \%$ & & & \\
\hline
\end{tabular}

Fig. 4), it is observed that the errors are typically distributed and falls on the ideal normal line. Residual versus fit diagrams also state that there is no time trend in residuals with fitted value. Secondly, the significance test of the individual term is checked using the $p$ value. It may be observed that linear terms AS and IF significant while FS is slightly insignificant. However, the $p$ value of the linear terms together is found to be very low. Thus all the linear terms are included in the model to avoid any ambiguity. It can also be seen that all the interaction terms are found to be insignificant. Therefore, irrelevant terms are reduced by backward elimination process one by one, and in each step, adequacy of the models has been checked. The ANOVA table for reduced models is presented in Table 4. $R^{2}$ is one of the most important statistics. From Table 4, it is seen that the difference between $R^{2}$ and $\mathrm{R}^{2}$-adj is minimal, indicating that the insignificant terms are removed from the model. From this analysis, the infeed appears to be the most influential factor in determining the mean thickness of the flow formed tube. The analytical expression for the mean thickness using this regression analysis is given below.

Mean thickness $=3.9147-0.0539 \times A S \_1-0.0080$

$$
\begin{aligned}
& \times A S \_2+0.0073 \times A S \_3+0.0545 \times \text { AS_4 }+0.693 \\
& \times I F \_1+0.2016 \times I F \_2-0.1873 \times I F \_3-0.7075 \\
& \times I F \_4-0.0634 \times F S \_1+0.0181 \times F S \_2+0.0102 \\
& \times \text { FS_3 }+0.0352 \times \text { FS_4 }
\end{aligned}
$$

The residual plot of the developed statistical model is shown in Fig. 4. In the normal residual versus fitted data, the former do not show a regular pattern. No time trend is noted for the observation for the standardized residual for the mean thickness of the flow formed tubes.

Table 4 Reduced regression model

\begin{tabular}{lcrcc}
\hline Source & DoF & Adj SS & F-Value & $p$ value \\
\hline Model & 9 & 17.0977 & 111.41 & 0.000 \\
Linear & 9 & 17.0977 & 111.41 & 0.000 \\
AS & 3 & 0.0960 & 111.41 & 0.145 \\
IF & 3 & 16.9107 & 330.58 & 0.000 \\
FS & 3 & 0.0911 & 1.78 & 0.162 \\
Error & 4 & 0.9208 & & \\
Total & 63 & & & \\
$\mathrm{R}^{2}=94.89 \% \mathrm{R}^{2}(\mathrm{adj})=94.04 \%$ & & \\
\hline
\end{tabular}

Fig. 4 Residual plots for mean thickness
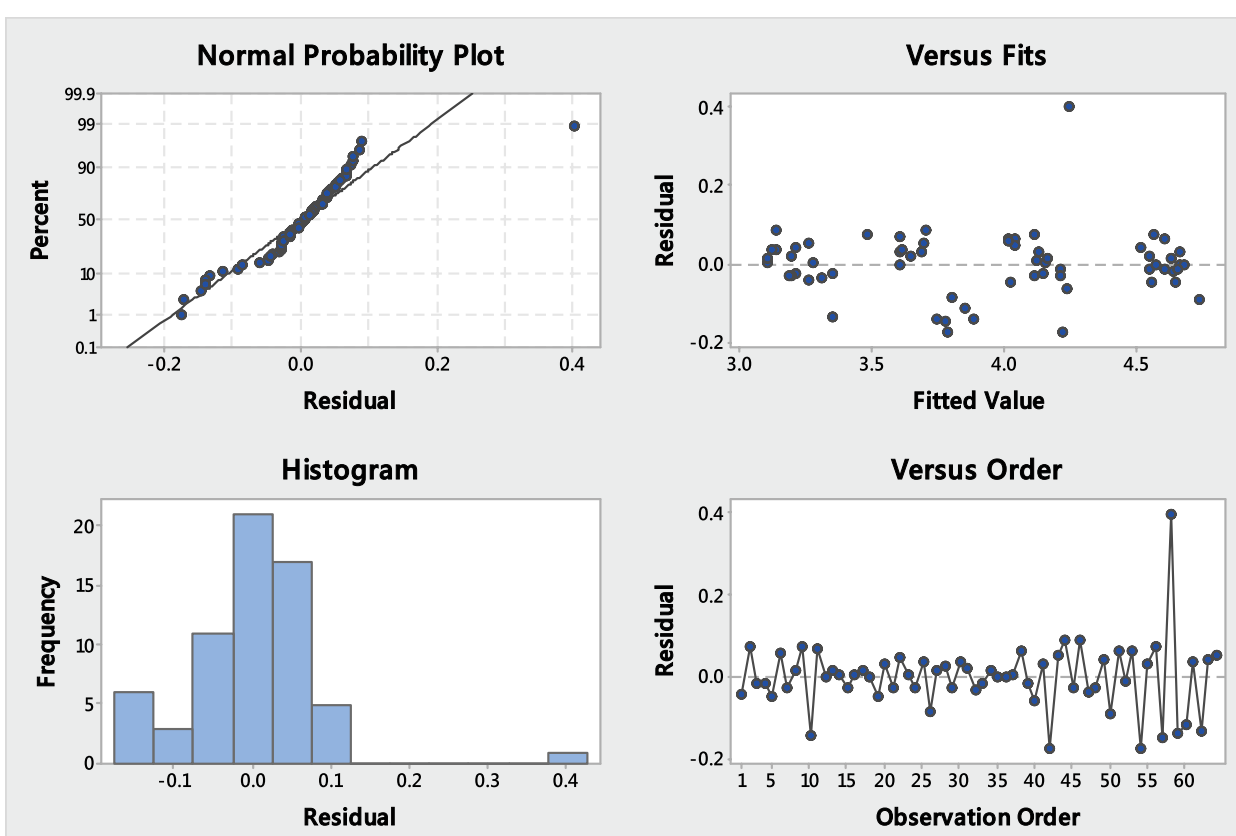
It also implies that the model does not underestimate the modeled mean thickness values with the progress of the experiments as per standard order. The normal probability plot of the residuals for the fitted data falls on a straight line, which indicates that the errors are normally distributed. Main effects (linear) plot is shown in Fig. 5. The different levels of the parameters (AS, FS, and IF) are coded as levels 1 to 4 . The main effect plots of axial stagger and feed speed ratio show less influence on the mean thickness. Since no interaction terms are present in the reduced model, therefore, the interaction plot is not analyzed. Miscandlon et al. [28] suggested that the wall thickness largely depends on the infeed of the roller. From this statistical analysis, it could be concluded that the infeed (IF) plays a critical parameter for modeling of mean thickness of the flow formed tube. Infeed (IF) is the main influencing parameter.

\subsection{Results of composite desirability}

One of the objectives of this research is to determine the optimal forming conditions for achieving a predetermined mean thickness. For realizing this, Composite desirability is preferred as it is one of the most widely used methods for optimization. Composite desirability is based on the weighted geometric mean of the individual desirability's for the responses on a range from zero to one. The individual desirability index of the responses is determined by transforming the corresponding response into the individual desirability function varying over a scale $0-1$, using the formula proposed by [29] as shown in Eq. (2). An ideal case is represented by 1 , while the worst case is indicated by zero. There are three forms of desirability functions, viz, (1) the lower-is the-better, (2) the higher-is-the-better and (3) the target-is-the-better,

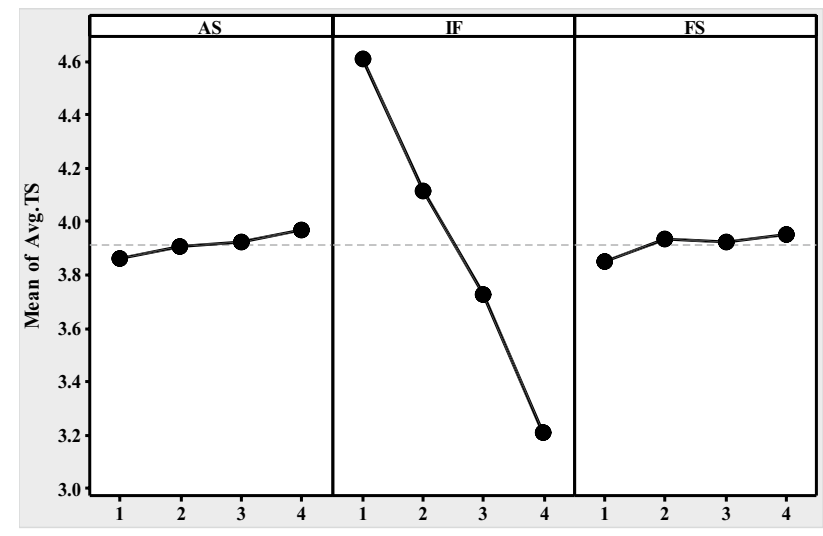

Fig. 5 Main effect of parameters for the response depending on whether the response is to be minimized, maximized or assigned to a target value.

$\left.d_{i}\left(x_{i}\right)=\left\{\left(\frac{x_{i}-x_{\min }}{T_{i}-x_{\min }}\right)^{r}\right\} \begin{array}{l}1 \\ 0\end{array}\right\} \begin{aligned} & x_{i} \leq x_{\min } \\ & x_{\min } \leq x_{i} \leq x_{\max }, w \geq 0 \\ & x_{i} \geq x_{\max }\end{aligned}$

where $X_{\min }, X_{\max }$ and $T_{i}$ represent the lower, upper, and target value of the responses, respectively. For this, a target is set, which is represented as 'target' in the Fig. 6 . The current parameter setting is represented in the middle row of the top of the column. The responses (mean thickness), predicted values of responses at the current parameter setting with individual desirability score is indicated at each row in the left column. From Fig. 6 , it could be seen that the optimized value is close to the target values. Also, for different targets $(3,3.5,4$ and 4.5$)$ the composite desirability is $(0.9413,0.9486,0.9875$ and 0.9459$)$ respectively. The predicted responses are also correlated with the experimental findings and are shown in Table 5. Based on the optimized values from the composite desirability approach, a set of experiments were performed to validate with the experimental findings (refer to Table 5), and it shows that the optimized values are very close to the experimental results. The findings of both the experimental and statistical methods show that the infeed and feed speed ratio inversely affects the mean thickness of the flow formed tube.

\subsection{Results of PSO and comparison with composite desirability function}

For the PSO, the maximum iteration was considered as 100 , and the population size was taken as 50 . The range of weights is made between 0.45 and 0.9. Table 5 shows the comparison of predicted values obtained from PSO with the optimum values obtained from the composite desirability technique. It is seen from Table 5 that the predicted values from the composite desirability approach are much closer to experimental values than PSO. As suggested from the ANOVA analysis, infeed is the most crucial factor, and thus higher desirability is given to that particular variable. Less preference is given to other remaining parameters. Whereas PSO is a search algorithm that tries to achieve the objective function in a given search space giving equal importance to all variables. 
Fig. 6 Prediction of the optimized value of responses using the composite desirability approach

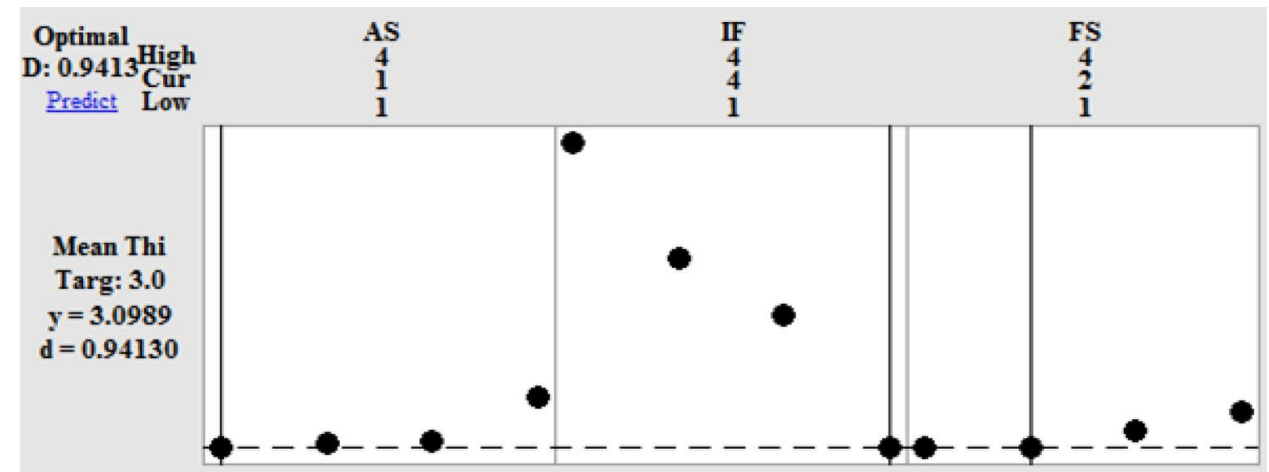

(a)

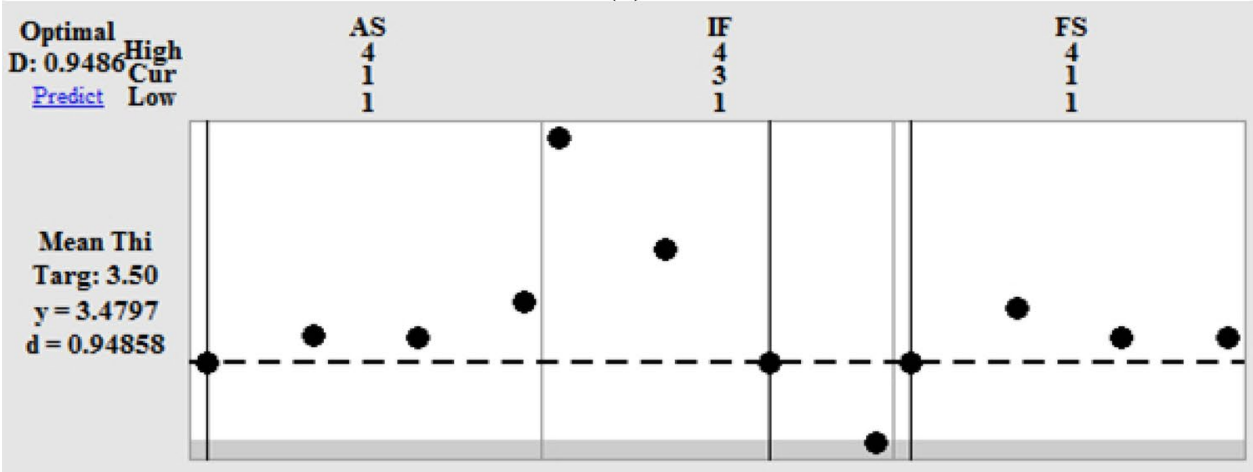

(b)

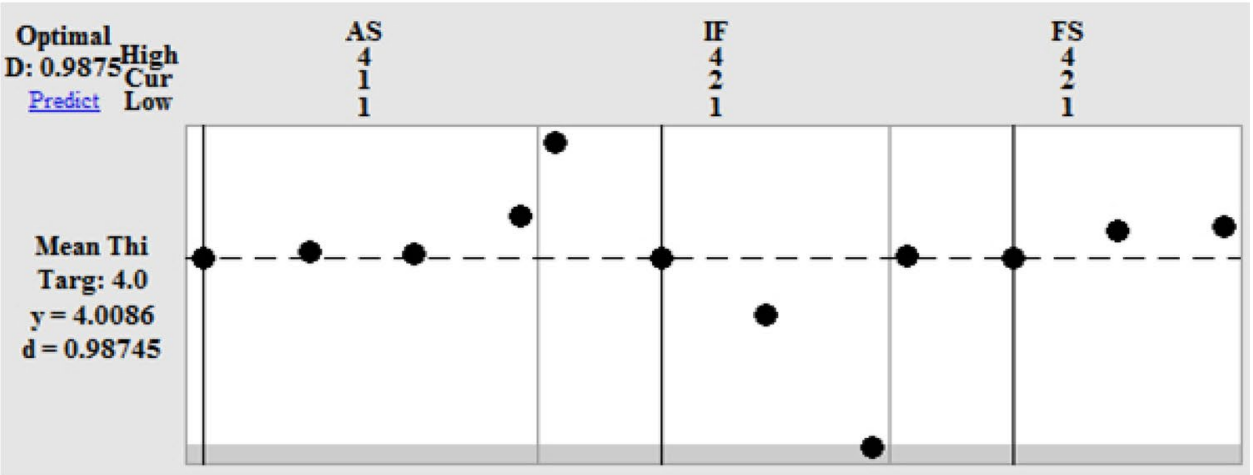

(c)

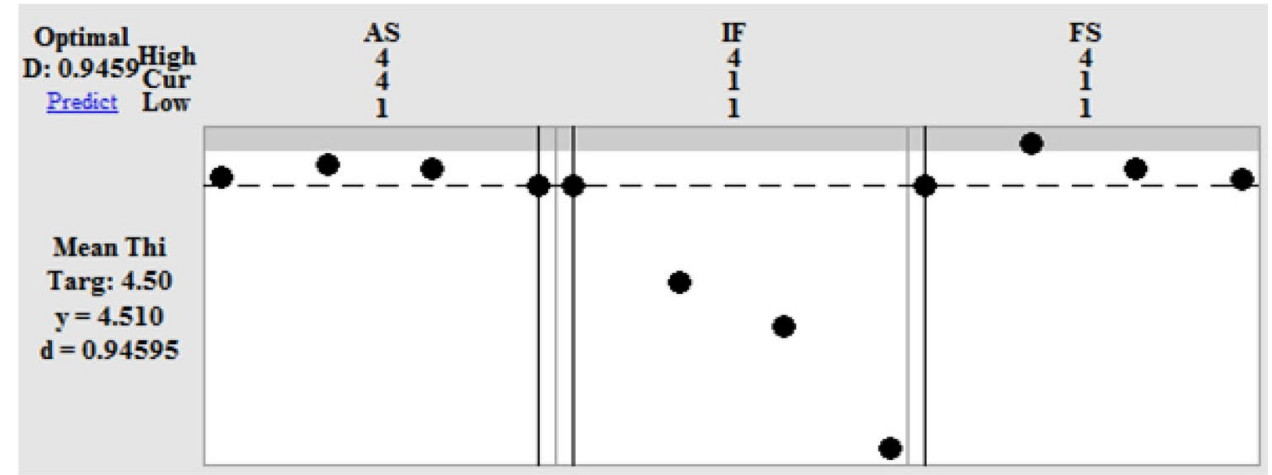

(d) 
Table 5 Prediction of mean thickness from different approaches of flow formed tubes

\begin{tabular}{|c|c|c|c|c|c|c|c|c|c|}
\hline \multirow[t]{3}{*}{ Target set } & \multirow[t]{3}{*}{ Experimental } & \multicolumn{4}{|c|}{ Composite desirability } & \multicolumn{4}{|c|}{ Particle swarm optimization } \\
\hline & & \multicolumn{3}{|c|}{ Optimized input parameters } & \multirow{2}{*}{$\begin{array}{l}\text { Mean thick- } \\
\text { ness }(\mathrm{mm})\end{array}$} & \multicolumn{3}{|c|}{ Optimized input parameters } & \multirow{2}{*}{$\begin{array}{l}\text { Mean thick- } \\
\text { ness (mm) }\end{array}$} \\
\hline & & $\mathrm{AS}(\mathrm{mm})$ & $\mathrm{IF}(\mathrm{mm})$ & $\mathrm{FS}(\mathrm{mm} / \mathrm{rev})$ & & AS $(\mathrm{mm})$ & $\mathrm{IF}(\mathrm{mm})$ & FS (mm/rev) & \\
\hline 3 & 3.105 & 9.5 & 4.5 & 0.5 & 3.099 & 11.907 & 3.437 & 0.515 & 3.514 \\
\hline 3.5 & 3.556 & 9.5 & 4 & 0.6 & 3.48 & 13.755 & 4.314 & 0.548 & 3.548 \\
\hline 4 & 4.068 & 9.5 & 3.5 & 0.6 & 4.009 & 9.838 & 4.277 & 0.646 & 4.00 \\
\hline 4.5 & 4.508 & 14 & 3 & 0.5 & 4.510 & 13.596 & 3.316 & 0.556 & 4.312 \\
\hline
\end{tabular}

\subsection{Results of the NN-based predictive model}

It has been reported in the literature that the performance of NN depends on its synaptic weights, and the number of neurons present in the hidden layer [27]. Initially, the number of neurons present in the hidden layer is varied from 3 to 15 one after another, and HSME for each case is noted. Similarly, the number of hidden layers is also changed from 1 to 5 , and the best architecture of the NN is indicated.

From Fig. 7a, it can be seen that the minimum error is obtained for eight neurons. Thus, for the employed model, the total number of neurons in the hidden layer would be eight, and the number of hidden layers would be 3. Once, number of neurons in the hidden layer and number of hidden layers are fixed, weights are then optimized using the back-propagation algorithm. Optimized NN architecture was then used to obtain the mean thickness for eight different test cases. Results have been received and compared with the regression model. It is important to note that 5 data sets were within the range considered during the experimental analysis, while the other 3 data set is outside the scale of the input parameters. The neural network performs well as the predicted values are very close to the experimental values. Table 6 shows the error percentage between the predicted values by the neural network technique and experimental values. The neural network is also able to efficiently predict the outcomes of input variables whose values are outside the range of training data sets. Thus, this neural network could be considered as an efficient, reliable model in the prediction of mean thickness at different sections of the backward flow formed tubes. Figure 8 shows the comparison of developed approaches for predicting the response versus target values. After that, a best-fit straight line in $\mathrm{y}=\mathrm{mx}$ format is drawn, and ' $m$ ' values by regression analysis and prediction by neural networks are found to be 0.9057 and 0.9105 , respectively. Since ' $m$ ' value for the neural network technique is higher than that of the regression technique, NN has the superior prediction capability.

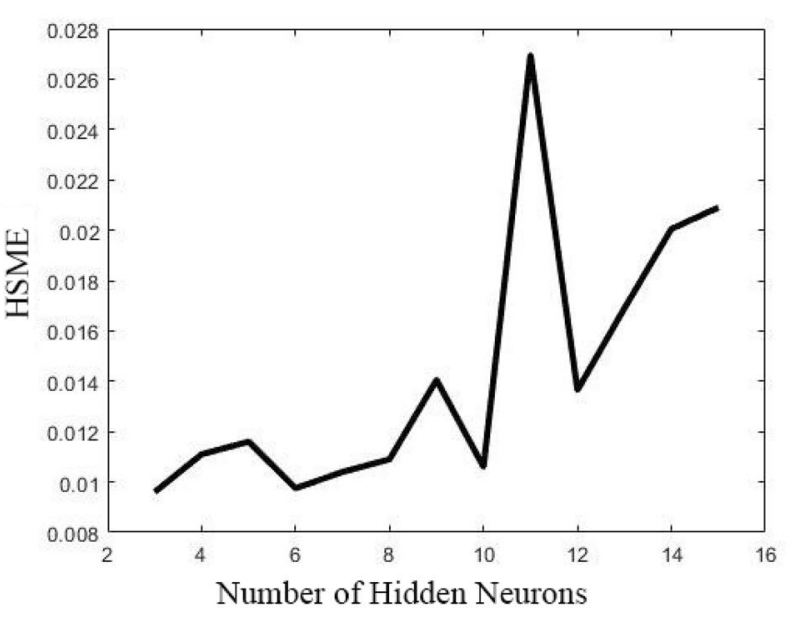

(a)

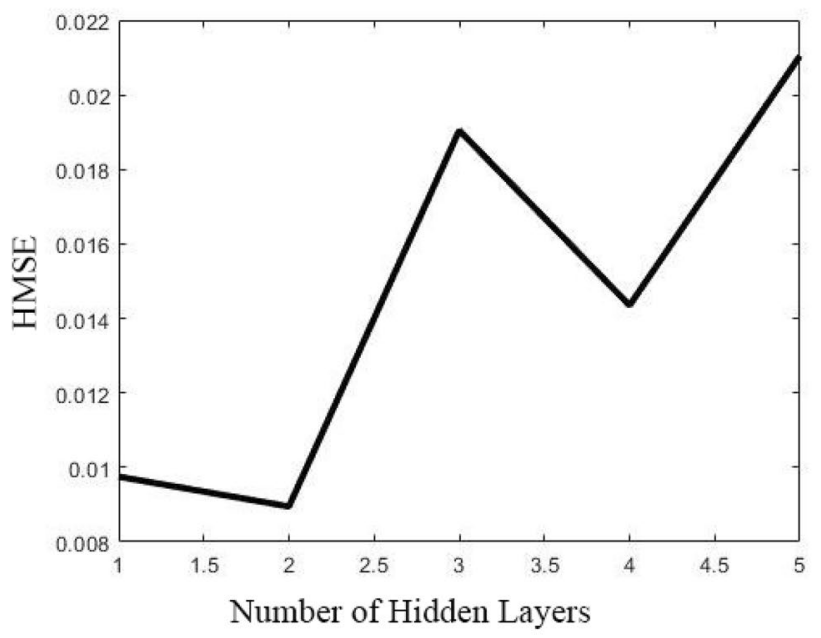

(b)

Fig. 7 a HMSE versus number of the hidden neuron. b HMSE versus number of hidden layers 
Table 6 Calculation of percentage error between the predicted and the experimental values

\begin{tabular}{|c|c|c|c|c|c|c|c|c|}
\hline \multirow[t]{2}{*}{ Data set no. } & \multirow[t]{2}{*}{ FS } & \multirow[t]{2}{*}{$\mathrm{IF}$} & \multirow[t]{2}{*}{ AS } & \multirow{2}{*}{$\begin{array}{l}\text { Mean thickness } \\
\text { (experimental) }\end{array}$} & \multicolumn{2}{|c|}{ Regression analysis } & \multicolumn{2}{|c|}{ Neural network } \\
\hline & & & & & Pred. & $\%$ Error & Pred. & $\%$ Error \\
\hline 1. & 0.55 & 3.7 & 12 & 3.459 & 3.6318 & 4.9948 & 3.29 & 4.8858 \\
\hline 2. & 0.75 & 4.2 & 12 & 3.394 & 3.4080 & 0.4119 & 3.1 & 8.6623 \\
\hline 3. & 0.65 & 3.2 & 10 & 4.36 & 3.7960 & 12.9358 & 3.84 & 11.926 \\
\hline 4. & 0.72 & 3.4 & 10 & 4.138 & 3.7062 & 10.4351 & 3.8266 & 7.525 \\
\hline 5. & 0.65 & 3.2 & 12 & 4.368 & 3.8642 & 11.5339 & 3.899 & 10.737 \\
\hline 6. & 0.4 & 2.8 & 9 & 4.56 & 3.9383 & 13.6329 & 4.03 & 11.622 \\
\hline 7. & 0.9 & 2.5 & 9 & 5.088 & 4.0905 & 19.6055 & 4.82 & 5.2672 \\
\hline 8. & 0.45 & 4.8 & 15 & 2.825 & 3.2262 & 14.2011 & 2.48 & 12.213 \\
\hline
\end{tabular}

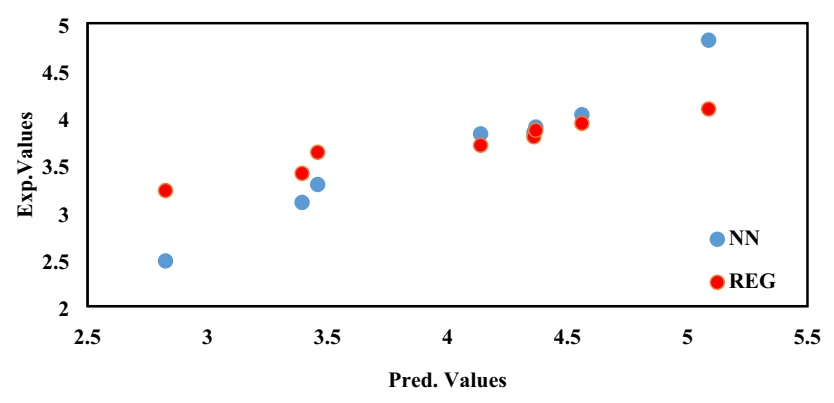

Fig. 8 Predicted versus the experimental values of the response

\section{Conclusions and scope for future work}

This study aimed at developing the relationship between the mean thicknesses of flow formed cylindrical tubes with three forming parameters such as axial stagger, infeed, and a feed speed ratio of rollers. From this study, the following conclusion could be made:

- An empirical relationship based on regression analysis is developed, and the mean thickness can easily be predicted from this model. The developed regression models for the responses can be considered useful as values of the R-sq, and R-sq (adj) is close to unity. Also, the difference between the said values is minimal, which suggests that the developed model is acceptable and robust.

- The effect of individual parameters is studied, and it could be stated that the infeed is the most crucial parameter. The low $p$ value and high $\mathrm{f}$-value obtained from ANOVA analysis ascertain the claim.

- A composite desirability approach is utilized to predict the optimized values for the responses. The predicted optimum values were in close agreement with the experimental data.

- PSO was also used to predict the optimized responses corresponding to input parameters for a given desired target value. In this investigation, the optimized value obtained from the composite desirability approach tends to perform better as the optimized value was close to experimental data.

- The regression equation is developed for the establishment of the relationship between the output and the input variables. However, the prediction capability of such a comparison was not satisfactory. Neural network topology is developed to model the three input parameters of the flow forming process. Eight test data are used, and the prediction capability was the best compared to regression analysis. The $\mathrm{NN}$ is also able to predict for the responses whose input values are considered outside the initial range of the experimental data. The error percentage, which signifies the deviation of the predicted values from the experimental values, for all the test case data is meager.

- The NN-based predictive model performed better compared to the regression analysis. It is because of the adaptive properties of the NN-based tool. This tool could be used for efficient prediction of mean thickness for the set of input parameters.

- The NN is optimized using the back propagation algorithm, and more global optimization techniques such as genetic algorithms (GA) may be used later for such purposes to get better prediction.

\section{Compliance with ethical standards}

Conflict of interest On behalf of all authors, the corresponding author states that there is no conflict of interest.

\section{Appendix}

See Table 7. 
Table 7 Experimental data

\begin{tabular}{|c|c|c|c|c|c|}
\hline Exp. no & Prform identification & $\begin{array}{l}\text { Feed-speed } \\
\text { ratio }(\mathrm{mm} / \mathrm{rev})\end{array}$ & INFEED (mm) & $\begin{array}{l}\text { Axial Stag- } \\
\text { ger (mm) }\end{array}$ & Thickness (mm) \\
\hline 1 & $1 \mathrm{H} 30010530095$ & 0.5 & 3 & 9.5 & 4.5075 \\
\hline 2 & $1 \mathrm{H} 30020630095$ & 0.6 & 3 & 9.5 & 4.6375 \\
\hline 3 & 1H30030730095 & 0.7 & 3 & 9.5 & 4.6325 \\
\hline 4 & 1H30040830095 & 0.8 & 3 & 9.5 & 4.6125 \\
\hline 5 & $1 \mathrm{H} 30050535095$ & 0.5 & 3.5 & 9.5 & 3.97 \\
\hline 6 & 1H30060635095 & 0.6 & 3.5 & 9.5 & 4.0675 \\
\hline 7 & 1H30070735095 & 0.7 & 3.5 & 9.5 & 4.1125 \\
\hline 8 & 1H30080835095 & 0.8 & 3.5 & 9.5 & 4.1725 \\
\hline 9 & 1H30090540095 & 0.5 & 4 & 9.5 & 3.555 \\
\hline 10 & 1H30100640095 & 0.6 & 4 & 9.5 & 3.5975 \\
\hline 11 & 1H30110740095 & 0.7 & 4 & 9.5 & 3.665 \\
\hline 12 & 1H30120840095 & 0.8 & 4 & 9.5 & 3.5975 \\
\hline 13 & 1H30130545095 & 0.5 & 4.5 & 9.5 & 3.115 \\
\hline 14 & 1H30140645095 & 0.6 & 4.5 & 9.5 & 3.105 \\
\hline 15 & $1 \mathrm{H} 30150745095$ & 0.7 & 4.5 & 9.5 & 3.1525 \\
\hline 16 & $1 \mathrm{H} 30160845095$ & 0.8 & 4.5 & 9.5 & 3.2725 \\
\hline 17 & $1 \mathrm{H} 30170530110$ & 0.5 & 3 & 11 & 4.64 \\
\hline 18 & $1 \mathrm{H} 30180630110$ & 0.6 & 3 & 11 & 4.5625 \\
\hline 19 & $1 \mathrm{H} 30190730110$ & 0.7 & 3 & 11 & 4.5925 \\
\hline 20 & $1 \mathrm{H} 30200830110$ & 0.8 & 3 & 11 & 4.685 \\
\hline 21 & $1 \mathrm{H} 30210535110$ & 0.5 & 3.5 & 11 & 4.085 \\
\hline 22 & $1 \mathrm{H} 30220635110$ & 0.6 & 3.5 & 11 & 4.0825 \\
\hline 23 & $1 \mathrm{H} 30230735110$ & 0.7 & 3.5 & 11 & 4.155 \\
\hline 24 & $1 \mathrm{H} 30240835110$ & 0.8 & 3.5 & 11 & 4.1775 \\
\hline 25 & $1 \mathrm{H} 30250540110$ & 0.5 & 4 & 11 & 3.6475 \\
\hline 26 & $1 \mathrm{H} 30260640110$ & 0.6 & 4 & 11 & 3.71 \\
\hline 27 & $1 \mathrm{H} 30270740110$ & 0.7 & 4 & 11 & 3.6625 \\
\hline 28 & $1 \mathrm{H} 30280840110$ & 0.8 & 4 & 11 & 3.71 \\
\hline 29 & $1 \mathrm{H} 30290545110$ & 0.5 & 4.5 & 11 & 3.16 \\
\hline 30 & $1 \mathrm{H} 30300645110$ & 0.6 & 4.5 & 11 & 3.155 \\
\hline 31 & $1 \mathrm{H} 30310745110$ & 0.7 & 4.5 & 11 & 3.2075 \\
\hline 32 & $1 \mathrm{H} 30320845110$ & 0.8 & 4.5 & 11 & 3.275 \\
\hline 33 & $1 \mathrm{H} 30330530125$ & 0.5 & 3 & 12.5 & 4.5875 \\
\hline 34 & $1 \mathrm{H} 30340630125$ & 0.6 & 3 & 12.5 & 4.5575 \\
\hline 35 & $1 \mathrm{H} 30350730125$ & 0.7 & 3 & 12.5 & 4.67 \\
\hline 36 & $1 \mathrm{H} 30360830125$ & 0.8 & 3 & 12.5 & 4.655 \\
\hline 37 & $1 \mathrm{H} 30370535125$ & 0.5 & 3.5 & 12.5 & 4.1225 \\
\hline 38 & $1 \mathrm{H} 30380635125$ & 0.6 & 3.5 & 12.5 & 4.0975 \\
\hline 39 & $1 \mathrm{H} 30390735125$ & 0.7 & 3.5 & 12.5 & 4.1925 \\
\hline 40 & $1 \mathrm{H} 30400835125$ & 0.8 & 3.5 & 12.5 & 4.1725 \\
\hline 41 & $1 \mathrm{H} 30410540125$ & 0.5 & 4 & 12.5 & 3.63 \\
\hline 42 & $1 \mathrm{H} 30420640125$ & 0.6 & 4 & 12.5 & 3.61 \\
\hline 43 & $1 \mathrm{H} 30430740125$ & 0.7 & 4 & 12.5 & 3.74 \\
\hline 44 & $1 \mathrm{H} 30440840125$ & 0.8 & 4 & 12.5 & 3.7825 \\
\hline 45 & $1 \mathrm{H} 30450545125$ & 0.5 & 4.5 & 12.5 & 3.18 \\
\hline 46 & 1H30460645125 & 0.6 & 4.5 & 12.5 & 3.2175 \\
\hline 47 & $1 \mathrm{H} 30470745125$ & 0.7 & 4.5 & 12.5 & 3.215 \\
\hline 48 & $1 \mathrm{H} 30480845125$ & 0.8 & 4.5 & 12.5 & 3.3225 \\
\hline 49 & $1 \mathrm{H} 30490530140$ & 0.5 & 3 & 14 & 4.5525 \\
\hline 50 & $1 \mathrm{H} 30500630140$ & 0.6 & 3 & 14 & 4.64 \\
\hline
\end{tabular}


Table 7 (continued)

\begin{tabular}{llllll}
\hline Exp. no & Prform identification & $\begin{array}{l}\text { Feed-speed } \\
\text { ratio }(\mathrm{mm} / \mathrm{rev})\end{array}$ & INFEED $(\mathrm{mm})$ & $\begin{array}{l}\text { Axial Stag- } \\
\text { ger }(\mathrm{mm})\end{array}$ & Thickness (mm) \\
\hline 51 & $1 \mathrm{H} 30510730140$ & 0.7 & 3 & 14 & 4.66 \\
52 & $1 \mathrm{H} 30520830140$ & 0.8 & 3 & 14 & 4.535 \\
53 & $1 \mathrm{H} 30530535140$ & 0.5 & 3.5 & 14 & 4.075 \\
54 & $1 \mathrm{H} 30540635140$ & 0.6 & 3.5 & 14 & 4.0375 \\
55 & $1 \mathrm{H} 30550735140$ & 0.7 & 3.5 & 14 & 4.155 \\
56 & $1 \mathrm{H} 30560835140$ & 0.8 & 3.5 & 14 & 4.185 \\
57 & $1 \mathrm{H} 30570540140$ & 0.5 & 4 & 14 & 3.6225 \\
58 & $1 \mathrm{H} 30580640140$ & 0.6 & 4 & 14 & 4.6375 \\
59 & $1 \mathrm{H} 30590740140$ & 0.7 & 4 & 14 & 3.7375 \\
60 & $1 \mathrm{H} 30600840140$ & 0.8 & 4 & 14 & 3.7325 \\
61 & $1 \mathrm{H} 30610545140$ & 0.5 & 4.5 & 14 & 3.17 \\
62 & $1 \mathrm{H} 30620645140$ & 0.6 & 4.5 & 14 & 3.21 \\
63 & $1 \mathrm{H} 30630745140$ & 0.7 & 4.5 & 14 & 3.2475 \\
64 & $1 \mathrm{H} 30640845140$ & 0.8 & 4.5 & 14 & 3.31 \\
\hline
\end{tabular}

\section{References}

1. Hayama M, Kudo H (1979) Analysis of diametral growth and working forces. Bull JSME 22(167):776-784

2. Nagarajan HN, Kotrappa H, Mallanna C (1981) Mechanics of flow forming. Ann CIRP 30(1):159-162

3. Thamasett $E$ (1961) Forces and limits of shape variations in stretch forming of hollow cylinder from aluminium. Max Planck's Institute of Metal Research, Stuttgart

4. Gur M, Tirosh J (1980) Plastic flow instability under compressive loading during shear spinning process. J Eng Ind ASME Trans 104(1):17-22

5. Singhal RP, Saxena PK, Prakash R (1990) Estimation of power in the shear spinning of long tubes in hard-to-work materials. $J$ Mater Process Technol 23(1):29-40

6. Chang SC, Huang CA, Yu SY, Chang Y, Chan W, Shieh TS, Chung HC, Yao HT, Shyu GD, Hou HY, Wang CC, Wang WS (1988) Tube spinnability of AA 2024 and 7075 aluminum alloys. J Mater Process Technol 80-81(1):676-682

7. Jahazi M, Ebrahimi G (2000) The influence of flow-forming parameters and microstructure on the quality of a D6ac steel. $J$ Mater Process Technol 103(3):362-366

8. Rajan KM, Deshpande PU, Narasimhan K (2002) Effect of heat treatment of preform on the mechanical properties of flow formed AISI 4130 steel tubes - a theoretical and experimental assessment. J Mater Process Technol 125-126:503-511

9. Molladavoudi HR, Djavanroodi F (2011) Experimental study of thcikness reduction effects on mechanical properties and spinning accuracy of aluminum 7075-0, during flow forming. Int J Adv Manuf Technol 52:949-957

10. Davidson MJ, Balasubramanian K, Tagore GR (2008) Experimental investigation on flow-forming of AA6061 alloy-a Taguchi approach. J Mater Process Technol 200(1-3):283-287

11. Nahrekhalaji AR, Ghoreishi M, Tashnizi ES (2010) Modeling and investigation of the wall thickness changes. Engineering 2:141-148

12. Aghchai AJ, Razani NA, Dariani BM (2012) Flow forming optimization based on diametral growth using finite element method and response surface methodology. Proc Inst Mech Eng Part B J Eng Manuf 226(12):2002-2012
13. Podder B, Banerjee P, Kumar KR, Hui NB (2019) Study of the influences of process parameters on cold flow forming of Al-tubes. Int J Mod Manuf Technol 11(1):95-106

14. Srinivasulu M, Komaraiah M, Prasad CS (2012) Experimental investigations to predict mean diameter of AA6082 tube in flow forming process - a DOE approach. IOSR J Eng 2(6):52-60

15. Wong CC, Dean TA, Lin J (2004) Incremental forming of solid cylindrical components using flow forming principles. J Mater Process Technol 153-154(10):60-66.

16. Parsa MH, Pazooki AMA, Ahmadabadi MN (2009) Flow-forming and flow formability simulation. Int J Adv Manuf Technol 42(5-6):463-473

17. Song X, Fong KS, Oon SR, Tiong WR, Li PF, Korsunsky AM, Danno A (2014) Diametrical growth in the forward flow forming process: simulation, validation, and prediction. Int J Adv Manuf Technol 71(1-4):207-217

18. Xu W, Zhao X, Ma H, Shan D, Lin H (2016) Influence of roller distribution modes on spinning force during tube spinning. Int J Mech Sci 113:10-25

19. Podder B, Banerjee $P$, Kumar KR, Hui NB (2018) Flow forming of thin walled precison shells. Sadhana 43(208):1-16

20. Han F, Mo JH, Qi HW, Long RF, Cui XH, Li ZW (2013) Springback prediction for incremental sheet forming based on FEM-PSONN technology. Trans Nonferrous Met Soc China 23:1061-1071

21. Kumar S, Singh AK (2019) Warpage and shrinkage analysis and optimization. J Adv Manuf Syst 18(1):85-102

22. Kim DJ, Kim BM (2000) Application of neural network and FEM for metal forming processes. Int J Mach Tools Manuf 40(6):911-925

23. Hsiang $\mathrm{SH}, \mathrm{Ho} \mathrm{H}-\mathrm{L}$ (2004) Application of finite element method and artificial neural network to the die design of radial forging processes. Int J Adv Manuf Technol 24(9-10):700-707

24. Ashhab MS, Breitsprecher T, Wartzack S (2012) Neural network based modeling and optimization of deep drawing - extrusion combined process. J Intell Manuf 25(1):77-84

25. Luca D (2015) Neural networks for parameters prediction of an electromagnetic forming process of FeP04 steel sheets. Int J Adv Manuf Technol 80(1-4):689-697

26. Podder B, Banerjee P, Kumar KK, Hui N (2018) Forward and reverse modelling of flow forming of solution annealed $\mathrm{H} 30$ aluminium tubes. Neural Comput Appl 32:2081-2093 
27. Pratihar DK (2008) Soft computing. Narosa Publishing House, New Delhi

28. Miscandlon J, Tuffs M, Halliday ST, Conway A (2018) Effects of flow forming parameters on dimensional accuracy in Mo-V steel tubes. In: 17th International conference on metal forming, Toyohahi
29. Derringer G, Suich R (1980) Simultaneous optimization of several response variables. J Qual Technol 12(4):214-219

Publisher's Note Springer Nature remains neutral with regard to jurisdictional claims in published maps and institutional affiliations. 